\title{
Informatization System Construction of the Historical Culture District
}

\author{
Yang $\mathrm{Hu}$ and Rong Han
}

\begin{abstract}
With the advance of global information process, the strategic significance of informatization has become increasingly prominent in the image dissemination process of historical culture districts. With the use of the Internet, cloud computing, artificial intelligence and other modern information technology, we can achieve the full-process, full-space-time and all-media integration, collaboration, optimization and promotion of historical culture districts in its dissemination, truly realizing information sharing and the efficient use of resources, and leading the historical culture district to a sustainable growth path. Based on the actual problems encountered in the informatization dissemination of the historical culture district, this paper analyzes the significance of informatization in the image dissemination process of the historical culture district and provides corresponding design strategies and dissemination ideas.
\end{abstract}

Index Terms - Historical and culture district, informatization, dissemination, media.

\section{INTRODUCTION}

The legal concept of the historical culture district has been clearly defined as: "historical culture district refers to the district approved and published by the local People's Government of province or municipality that is of abundant preserved cultural relics and concentrated historical buildings and can completely and truly reflect the traditional pattern and historic features with a certain amount of area" in Regulations on Protecting Historical Famous Towns and Villages (State Council Decree No. 24) implemented since July 1, 2008. The proposed definition plays a significant role in the image dissemination of historical culture district, and can avoid those districts falling into the embarrassing situation of not having a good reputation. The out break of information technology revolution, information economy and information society, and great theoretic and practical wave of social informatization and information socialization in twentieth century, both dramatically expanded human horizons, changing human's overall understanding and thinking way, and also changed human's political, economic, military, cultural, educational and life style and means in an all-round way [1]. And the rapid development of digital information industry also make informatization have great impact on all levels of society, thus the application of informatization policy to the image promotion of the historical culture district is of great importance.

Manuscript received February 5, 2015; revised June 10, 2015. This work was financially supported by culture research project "Research on Image Integration and Environment Renovation Methods of Historical Villages in Zhenjiang City" of Jiangsu province (Project No.:13YB24).

The authors are with the Jiangsu University, Zhenjiang, Jiangsu Province, China (e-mail: 20851399@qq.com, 33315935@qq.com).

\section{Status AnAlysis of the Historical CUlture DISTRICT INFORMATIZATION DISSEMINATION}

\section{A. The Unitary Dissemination Content}

Information age has entered every corner of society at all levels with an irresistible tendency to fully participate in people's life. Similarly, the image dissemination of historical culture district is affected by various new media and faced with the transition of visual communication (Fig. 1). Visual communication not only uses the way of "seeing” , but also tickles the auditory sense, tactile sense and other sense organs based on "seeing" , to provide people with all-round and three-dimensional sensory experience, which is of great attractiveness to audiences.

Each historical culture district has its own unique geographical environment and long-time cultural origins, which are key elements attracting the attention of the public and can be presented to the pubic with the most innovative way. In terms of the information dissemination chain, its source must be the information source of informatization, and the current dissemination contents of the domestic historical culture district are dominated by the combination of text and standard graphics. Even if some of the historical culture districts adopt the promotion way of network, their network still remain in the stage of static pages and with defects of slow-update of information, low click rate, lag feedback and so on, and they do not take the image dissemination effectiveness of historical culture district into account. Under the impact of the information age, "it cannot survive without the change of knowledge nature, and only when knowledge is transformed into batch information, can it become operational and applicable information with the use of various new media. Even it can be predicted: inside the knowledge constitution system, everything that can not be transformed and transported will be eliminated." [2]. The dissemination and inheritance of historical culture in the information era urgently needs the "transformation and transportation" achieved by modern media.

\section{B. Disorder Tendency of Dissemination Channels}

"If we say that in the 1830s,people just took newspaper and magazine as a way to understand the world; then for people today, the mass media are all channels used to get into social life." [3] Although various media have become an important channel for people to understand the community and the world, the way of image communication must also be changed. Today most of the historical culture districts do not realize the importance of the media integration. First, they do not have a scientific way to select the optimal mode of dissemination, but blindly use a variety of media, leading distraction and fragmentation of the audience attention; secondly, all links lack a systematic consideration of long-term goals, and various dissemination ways are directly 
divided into blocks, which are all in a muddle; then, although the diversity of dissemination ways in some areas enhance the productivity of information in a short term, they fail to conduct a good diversion, causing the audience to be inundated by overwhelming information, failing to correctly understand substantive characteristics of the image, not alone the connotation of the district. Those three points mentioned above lead the information dissemination of historical culture districts to mutually interference, which is not conducive to the image building of the historical culture district, and will gradually break down the established district image. In response to changes in the dissemination mode of the information age, historical culture districts urgently needs to integrate various modes of dissemination.

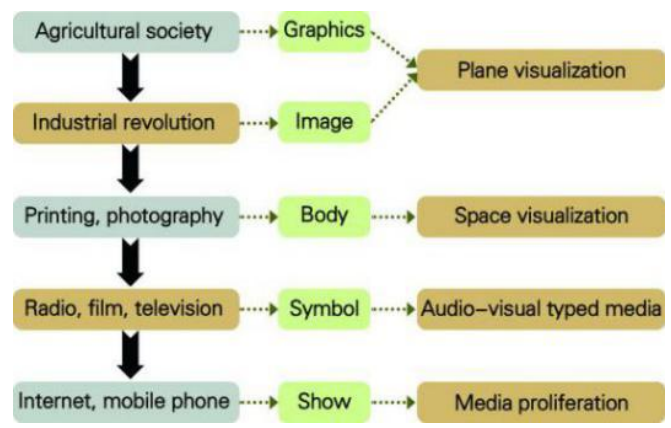

Fig. 1. The transition of visual communication.

\section{Hysteresis of Dissemination Media}

Objectively, the information dissemination media of historical culture districts directly affect the information availability of the audience, and as opposed to traditional tourism promotional materials, radio, television and other media, the emergence of the Internet provides a more convenient carrier for the information processing, storage and dissemination of historical culture districts, which can quickly become one of the most important ways for the audience to get the tourism information. With the application of radio-frequency technique, Internet of Things, cloud computing and other new information technologies, smart phones and other service terminals are constantly emerging, which provide a wider choice space for public tourism information service media. However, currently the intelligent application of most information dissemination media of historical culture districts is not enough, because they still use some relatively plain applications and do not conduct innovative dissemination media research or in-depth application, for example, they do not conduct application of the emerging micro-blog interaction, audio-visual software download, simulation experience of virtual reality scene, three-dimensional geographic coordinate system-based peripheral-information software download recommendation and other means. Thus, the isolation and non-communication among various media create information barriers.

\section{INFORMATIZATION DISSEMINATION IS A NECESSARY WAY FOR THE SUSTAINABLE DEVELOPMENT OF HISTORICAL CULTURE DisTRICTS}

\section{A. Deepen the Context Popularization and Promotion of Historical Culture Districts}

Since modern people's consumption tastes increasingly become cultural, artistic and high-style, cultural needs have become an important criterion for their selection. Today's the information digitization has provided excellent conditions for the culture dissemination of historical culture districts. Besides, China now has a huge number of target consumer groups of digital information. The statistic data of the 34th China Internet network development state statistic report show that: up to June 2014, the number of China's netizens has reached 632 million, and among them mobile phone netizens account for 527 million; the Internet popularizing rate is $46.9 \%$ [4], which is increasing year by year (Fig.2). This data indicates that information technology can explore huge space for the context promotion of historical culture districts. Information digitization is taking creativity as a driving force, and it combines all kinds of cultural resources and digital information technology to achieve the digitization dissemination of information through high-end technology, which can create considerable social and cultural values. At the same time, it requires to integrate the digitization development of historical culture districts and information technology, digital technology and network technology, which can enhance the spread power and creativity of the historical culture district context and then explore a new development space for the district context resources; on the other hand, as an integral part of the digital content industry, informatized context resources can also provide rich cultural digital materials for historical culture districts. Integrating the context resources of historical culture districts into the digital information technology industry will not only fully present the cultural value of historical culture districts, but also use technology to explore the digital material of the existing context resources and then take the advantage of resource reorganization to promote the healthy development of the context resources inheritance of historical culture districts and guide them to the path of sustainable development.

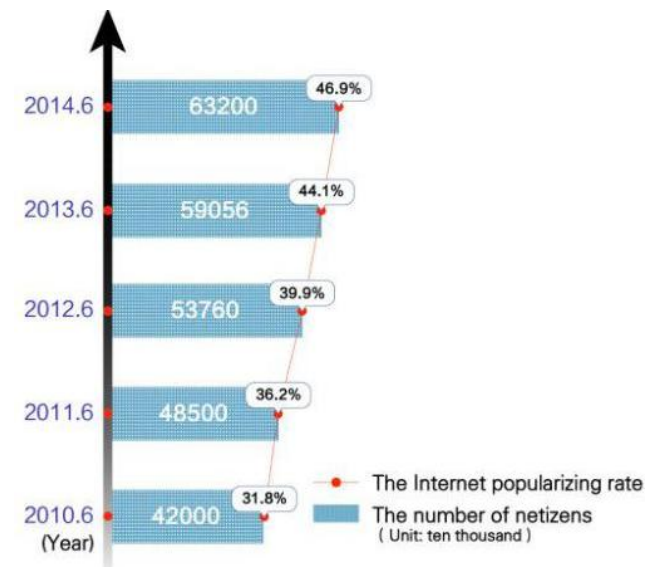

Fig. 2. The number of netizens and the Internet popularizing rate of the latest five years From: CNNIC China Internet network development state statistic survey.

\section{B. Promote the Visual Leading-in of the Historical Culture District Image}

Information technology has explored a broad information exchange platform for historical culture districts, and the feature of information digitization (Fig. 3) has promoted the visual leading-in of historical culture districts. First, information digitization is interactive, and it can change the audience from a passive information receiver into a positive participator with a distinctive autonomy through the modern information technology processing to take part in the entire activity process. For example, in the mobile phone terminal 
APP “Zhangjiajie” (Fig. 4), the information selection based on the audience's needs will help to achieve the true interaction between the historical culture district and the audience, and to shorten the distance between them, thereby expanding the image dissemination of historical culture districts. Secondly, the information digitization is virtual, while digitization is the non-reality entity. And the information storage, reproduction and dissemination based on digital media are more visual, faster and cheaper than the brand image disseminated by the print media. [5] And the information management, maintenance, and dissemination based on digital technology can provide a powerful platform and technology support for historical culture districts. Thirdly, the information digitization is open. The effective link established by various electronic devices can help the audience to exchange, consult and obtain relevant historical culture district information on its digital information platform This information exchange based on information digitization is audience-oriented, which not only breaks the time, place and space constraints between the historical culture district and the audience, but also shortens the communication and feedback distance and enhances their new image in the digital age.

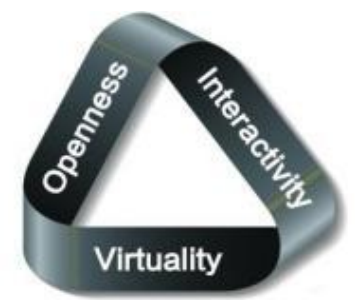

Fig. 3. Characteristics of information digitization.

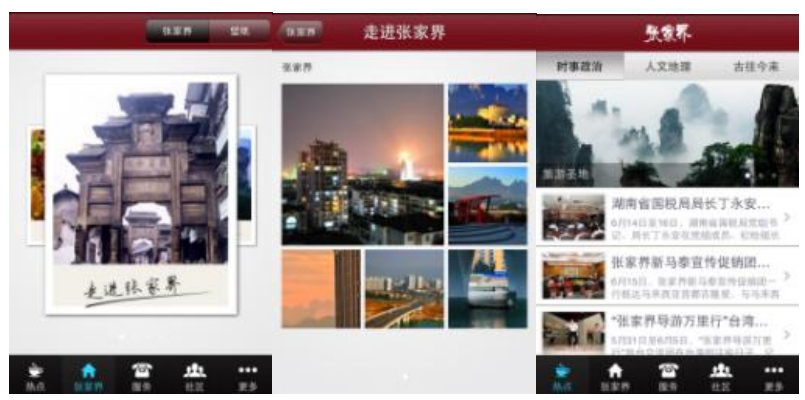

Fig. 4. Mobile phone terminal APP-Screenshots of "Zhangjiajie".

\section{DESIGN STRATEGY OF INFORMATIZATION DiSSEMINATION OF HiSTORICAL CULTURE DisTRICTS}

\section{A. Interactive Experience of Multiple Sensory Organs}

Martin Lindstrom, the global Chief Brand marketing guru finds through his study that in any means of dissemination, the importance of human's five senses makes no distinction of rank. From a cognitive standpoint, for the receptor of the dissemination-people, their five senses, including vision, hearing, smell, touch and taste, are basics of cognition as well as its sources. Cognitive psychology also describes the interaction process between men and the outside world from the viewpoint of information processing, and it decomposes the cognition into the product of a series of stages and operations (Fig. 5); then the entire series of integration is the achieving process of the interaction between men and the outside world. Therefore, the dissemination means should be extended from the form of a static image-text to the dynamic visual videos and the interpersonal interaction, which will create a new interaction way, interaction processes, expression forms and performance results, constructing a more complete historical culture district image. In addition, this way can allow the same disseminated information of historical culture districts to have the corresponding form on different media. The public information can not only be limited to certain historical culture district website, but can provide a full range of information services to the audience through computers, mobile phones, touch screen, digital TV and other devices. It is required to upgrade the existing website and focus on enhancing the multi-interface and multi-sensory information services; establish an information service screen system, and realize the unified information release and management on the self-service touch screen, the LED screens in consulting center and other information screens, achieving the dissemination of travel information on wide-range and more-interaction media.

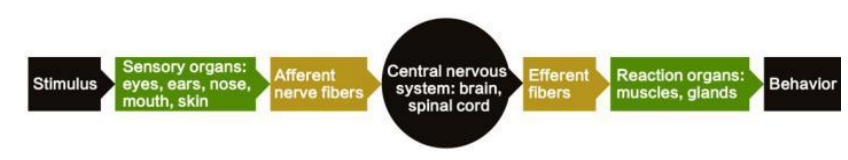

Fig. 5. Cognitive process of cognitive psychology.

\section{B. Optimization and Integration of Dissemination Channels}

The optimization and integration of information dissemination channels of historical culture districts is to take the advantage of various media to achieve the most effective contact with the audience. The selection of multiple media forms for the integration is not only to simply assembly or overlay them, but to find the best dissemination means for historical culture districts, and then take it as the basis to complete the integration with other means. Xijin Ferry of Zhenjiang is an ancient street with a thousand years of history, and the following data are obtained after the investigation of visitors' information acquiring channels:

The investigation data show that the Internet, television and newspaper are the most important ways for the audience to get the information of Xijin Ferry; and the main ways of dissemination can be divided into language media, text media and visual media, together constituting the dissemination mode of historical culture districts (Fig. 6). Language media is to orally exchange information among people, which is spontaneous with timely feedback and high interaction frequency; text media takes a variety of text as the medium of dissemination, which is strongly preservable, but of slow dissemination speed, and besides its dissemination effectiveness is limited by the audience's cultural level and comprehension ability; visual media is a flexible way with a fast spread and wide coverage, and its strong sense of the scene can deeply affect the audience's emotions. In the diversified integration of ways of dissemination of historical culture districts, it is required to achieve the complementary advantages of the selected media, and be able to disseminate information through different channels. On the one hand, the combined media must be complementary, in other words, the combined media should allow the information to be available 
to the audience that can not be contacted by other media; besides, the combined media must coordinate the broadcast or publication period, and assign the appropriate dissemination task to different media; and finally, to optimize the efficiency of the combined media and to achieve the best dissemination effectiveness, it is required to highlight the extent of the effective access and to master the time and frequency of information publishing and broadcasting. The actual dissemination activities should not limit forms of the integration of diverse dissemination means, but should make a flexible arrangement according to the actual situation.

\begin{tabular}{llll} 
TABLE I: MAIN CHANNELS TO OBTAIN THE INFORMATION OF XIJIN FERR \\
\hline \hline & $\begin{array}{l}\text { Number of } \\
\text { people }\end{array}$ & Percentage \\
\hline \multirow{5}{*}{ Dissemination } & Network & 207 & $35 \%$ \\
channels & Newspaper & 92 & $15.5 \%$ \\
& Magazine & 61 & $10.3 \%$ \\
& RV & 97 & $16.3 \%$ \\
& Books & 12 & $2 \%$ \\
& City visiting & 41 & $8.9 \%$ \\
& Others' & 31 & $6.9 \%$ \\
Total & introduction & $5.2 \%$ \\
\hline \hline
\end{tabular}

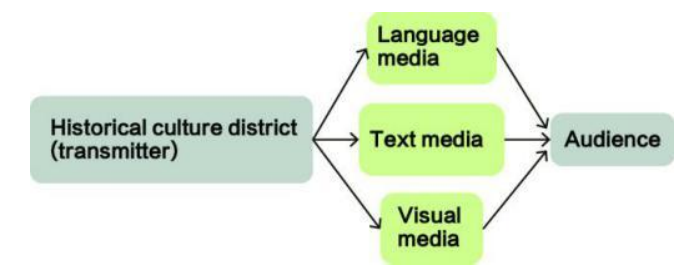

Fig. 6. Information dissemination mode.

\section{Upgrade of Digital Media Technology}

Enhancing the digital dissemination of historical culture district will make the information dissemination step off the monotonous text. It will present the historical and cultural knowledge targeted to be disseminated by historical culture districts with the form of video and three-dimension to the audience, in order to mobilize people's thirst for knowledge and inspire the audience to further explore the information. On the one hand, we can enhance the information database of historical culture districts through cloud computing, and apply the technology of "the integration of three networks" ${ }^{1}$ to websites and broadcast networks, to achieve the inter-communication of information. And government administration department can use cloud computing to build a public information platform for historical culture districts; then public information of historical culture districts can be stored in the cloud computing center, and the audience can directly query it on the cloud computing platform. On the other hand, the mobile terminal channels will increasingly

\footnotetext{
${ }^{1}$ The integration of three networks refers that during the evolution of telecommunications networks, broadcast networks and internet into the broadband communication network, digital television network and next-generation internet, technical capabilities of these three networks will converge through technological innovation, and also their business scope tends to be the same. Consequently, the network interconnection and interworking and resource sharing can provide users with a variety of voice, data and broadcast television services.
}

become the dependable information acquired channels of the audience. And as the traditional terminal server, digital information kiosk and tourism touch screen are replaced by smart phones, tablet computers and smart mobile terminals, forming a new access to information acquisition. Then historical culture district can take the digital map as the basis and combine GPS positioning and search capabilities to provide the audience with words, pictures, audios and other forms. In addition, to integrate the unique cultural connotation of historical culture districts with information technology integration, we can take the advantage of the exhibition, cultural celebrations and other events to demonstrate the application of information technology and promote information technology applications.

\section{CONCLUSION}

Integrating the image dissemination of historical culture districts into the information age plays a significant role in promoting the sustainable development of historical culture districts, and it can bring them new opportunities for further development. As for the reasonable application of modern information technology, network technology and new media is the new subject faced and needed to be solved by the industry, and even the whole society in the future period of time.

\section{REFERENCES}

[1] K. Wu, "Material thinking, energy thinking and energy thinking: Three big leaps of human thinking mode," Journal of Academics, 2002.

[2] J. F. Lyotard, The Postmodern Condition: A Report on Knowledge, Changsha: Hunan Fine Arts Publishing House, 1996.

[3] F. Kui, Media Worship - Differential Relationship between Modern People and the Mass Media, Beijing: China Communication University Press, 2008.

[4] The 34th China Internet network development state statistic report, 2013.

[5] Q. Chen, "The research on the expression characteristics of digital media ARTS," Master's thesis, Shandong Normal University, Jinan, 2009.

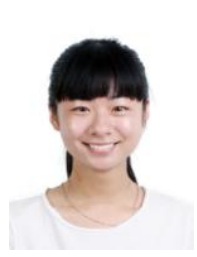

Yang Hu was born in Suzhou City, An Hui Province, in 1992. She is currently pursuing a master degree in Jiangsu University, where is in Zhenjiang city, Jiangsu Province, China. As a master student, the research field of her is directed to design of information system.

She has won several contest honors associated with the major field and school scholarships since she join in the university. Not only has she been engaged in teaching assistant, but also has participated in the research on SPBL architecture environment by using the graduate design practice base construction and other project research.

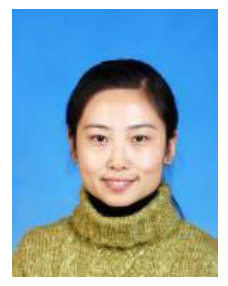

Rong Han was born in Qingdao City, Shandong Province in 1976. She got her Ph.D degree from Soochow University, and works as an associate professor currently in Art school of Jiangsu University. Her research interests include environmental resource integration and information processing.

She has published more than 30 professional papers, and four monographs. The publisher is respectively SDX Joint Publishing Company, The Commercial Press and People's Daily Press. 